\title{
An activity theory of research methods in architecture and urbanism
}

Michael AR Biggs

\begin{abstract}
Background: Using activity theory this article argues that intentional activities are central to knowledge-production and may be compared to methods in research, and the worldview within which these activities are perceived as meaningful by the actors who deploy them may be compared to methodologies. Accordingly, research activities are dependent on their context and cannot simply be transferred from one context to another.

Methods: Taking the scientific method as an example, the article discusses the underlying materialist assumptions that give the scientific method its meaning, and that helps to identify selective data as evidence for its propositions. By exposing this process as one of narrative construction that is situated and given meaning by the community that deploys it, the article argues that alternative narratives are possible and argues against the assumption that data and evidence are neutral or objective. The purpose of this argument is not to undermine the scientific method, but merely to show that its power lies in the strong connection between the worldview of science and the methods it employs for its development, with the intention of providing a similarly robust framework for architecture and urbanism.

Results: The article rejects ontological and epistemological accounts of knowledge production in favour of a socio-cultural approach that sees a community of academics and professionals, such as those in science or in architecture and urbanism, as an interpretative community of shared values and beliefs. These communities share fundamental views about the nature of their disciplines and what is important within them. As a result they determine through their practices what kind of questions are important and what kind of responses are meaningful.

In the field of research, they also determine what research outcomes are significant and impactful, and hence represent an advance or knowledge production in the field.
\end{abstract}

Conclusions: On this basis, a proposal is made in which architecture and urbanism is one such interpretative community supporting methodologies and research methods, resulting in a framework for the further development of research practices and research by design.

Keywords: Research; academic; professional; values; community; methods; impact; meaning; significance

\section{Background}

According to activity theory, we construct our reality as a consequence of our actions. Who we are, and what we do, does not only define us in the eyes of those around us, but also determines how we see the world and what it offers us. For example, Gibson (1986 [1979]) formulated his notion of "affordances" as a way of explaining how it is that some situations and objects seem to present themselves to us as things we can use. Wittgenstein (1953) talks about "language games" in which we share common attitudes towards

Correspondence: m.a.biggs@herts.ac.uk

School of Creative Arts, University of Hertfordshire, College Lane, Hatfield AL10 9AB, UK the world and what it presents to us. These accounts, and many others, present a constructivist worldview in which we make or construct an interpretation of the world that facilitates certain interactions and limits others. This constructivist worldview can be contrasted with the scientific worldview in which everything about the real world lies out there to be discovered, independently of our attitudes or interpretations of it. Popper (2002 [1963]) has problematized this 'naïve', Realist account of the scientific worldview by pointing out that science is just as speculative as other disciplines, and that notions of disinterested deductions based on neutral data or evidence are unrealistic accounts of the kind of motivated or hypothesis-driven actions that

\section{슬}


scientists actually undertake in the laboratory in pursuit of the confirmation of their goals. Feyerabend (1993 [1975]) has argued that even the claims of motivated or hypothesisdriven actions cannot really be defended and science is a much more creative and arbitrary business than is stereotypically assumed. Latour and Woolgar (1986) have exposed the human, interested, motivated world of the science laboratory that is usually excluded from accounts of scientific enquiry, and Bloor (1991 [1976]) has taken this further by arguing that all kinds of knowledge, including the most apparently human-independent, is motivated and arises in a context of values and beliefs.

In response to the postmodern scepticism about the possibility of independent, value-free and belief-free knowledge production and the truth-claims of contemporary science, one can find debate about what methods should be required to improve the validity and reliability of research, and even whether these requirements are fundamental. The exact meaning of the notions of validity and reliability are context-dependent having, for example, different interpretations when applied to quantitative or qualitative data and methods. Indeed, in creative arts including architecture and urbanism, music, etc., there is disagreement about whether validity or reliability have any meaning in research. Nonetheless, in all areas, the general idea of how our practical actions can be mobilised into knowledge-production activities is a topical academic issue.

According to activity theory, an activity is an organised set of actions that combine together to construct our reality (Engeström et al. 1999). Activities are therefore central to knowledge-production. We can consider activities as corresponding to methods in research, and the worldview within which these activities are perceived as meaningful by the actors who deploy them, as methodologies. Methodologies are value and belief sets that provide an interpretative framework for understanding the impact and significance of those activities.

Wittgenstein tells us that something is an answer to a question when it makes that question go away (1953) questioning is a kind of malady, a disquiet, that requires the remedy of a particular response for us to feel calm again. If we are architects, and our interest lies in the uses of architecture to understand the world, then our issues and concerns are going to be architectural, in the sense of "related to architecture", and the responses that we seek are going to be architectural too. Sociological or astronomical responses are not going to satisfy us if we have an architectural question: only an architectural answer will satisfy us. Thus all our questions, and what we take to be answers to them, occur in a context, for example architecture or astronomy.

In research terms we occupy a worldview in which certain issues are meaningful and others are not. The term "meaningful" is adopted from Hirsch (1984), and refers to whether something is relevant to our field of interest. Similarly, certain responses or methods are going to be productive, or "significant" as Hirsch would say, and others are not. In any one research project, our research methodology or activity is going to determine a set of methods or actions that are deemed appropriate by ourselves and by our peers, with the potential to produce a significant response to our research question or issue. Ensuring the relevance, appropriateness and productivity of our method is part of making a research proposal, and explains how it is that we can write a proposal in a creative area such as architecture. An architectural research proposal does not anticipate the outcome of the research, as does the hypothetico-deductive scientific method, nor does it stifle creativity or serendipity. An architectural research proposal agues that undertaking a specified series of actions is a meaningful activity for the community of architect-peers who represent the users of the research outcomes. Coyne, writing about architects, describes such peer groups as "interpretative communities" in which "words and ideas are always half someone else's" (Coyne 2009). A successful research proposal therefore satisfies its interpretative community that the proposed activities are meaningful and therefore have the potential to produce outcomes that are significant to them (Hirsch 1984).

Situating activity in a social context and in an interpretative community of users also provides us with evaluative tools, not only for assessing the appropriateness of the proposed methods, but also of assessing the appropriateness of data. In any given context, some things may count as data and others not. For example, in a murder trial, the blood on a blood-stained knife may be considered data relevant to the trial, but in a cookery competition it simply shows that basic hygiene standards have not been observed. Information only becomes data in relation to an objective. Data-gathering is therefore a constructive activity that reveals or responds to a worldview in which the information that is gathered has some use in relation to an activity. In considering the question of whether "doing architecture is doing research", Till adopts an activitytheoretic model of architectural research when he says that "to add to the store of knowledge, we need to understand the process that led to the object" (Till 2011).

\section{Methods}

This generic activity-theoretic account of research and knowledge production can now be used to discuss certain issues regarding research in creative arts [broadly construed to include creative aspects of arts, music, performance, architecture, etc.], and specifically to discuss the issue of validity in research and evaluation methods. The account can either be used to determine whether a particular method or action is appropriate in relation to a situated question, or it can be used to reveal the underlying methodological assumptions or worldview held by the advocates of a particular activity. In other 
words, one can use an activity-theoretic account to explain why an architectural activity is appropriate in response to an architectural question, i.e. a question posed in the context of architecture; or one can use it to identify the architectural worldview and values within which a response is perceived as meaningful by the interpretative community of architects. Within any particular worldview, certain data will be selected by the community as evidence for its research and other data will be overlooked or rejected.

The introduction of evidence-based assessment presents some interesting challenges for areas such as creative arts. On the one hand, it seems undeniable that decisions about funding or the evaluation of quality should be based on some kind of evidence. The counter position would seem to be absurd: that we should make decisions without evidence. But the question immediately arises, what constitutes evidence in such areas? This question, and related ones such as the impact on decision-making of choosing one kind of data over another as evidence, has plagued the design of research assessment systems around the world including the Australian "excellence in research for Australia" [ERA], the New Zealand "performance-based research fund" [PBRF], and the UK "research assessment exercise/research excellence framework" [RAE/REF], etc.

The assumption normally made in the design of research assessment and quality assurance systems - that by grounding our decision-making in evidence we are somehow protected from error - can be easily challenged. Take, for example, a commonplace example of the courtroom and how evidence is used. In the British court there is a requirement known as disclosure. Disclosure means that all of the evidence that will be produced in court is disclosed in advance by the prosecution to the defence and vice versa. As a result no new evidence is presented in court and none of the evidence that is used comes as a surprise to either side. One can therefore see that the basis for the argument presented by the prosecution is a singular narrative woven from the shared evidence, rather than being based in the use of different evidence from that deployed by the defence. This is itself is sufficient to show that a particular argument or outcome is not solely determined by the evidence that is used. In the courtroom we regularly see two different narratives being woven from the same evidence. Indeed, in the courtroom these narratives point to two completely opposed outcomes: guilt or innocence. It is the brief of the prosecution to assume that the defendant is guilty and to construe the evidence in such a way as to demonstrate that guilt. On the other hand, it is the brief of the defence to assume the innocence of the defendant and to construe the same evidence in such a way as to demonstrate that innocence. This reveals that it is false to assume that data alone, or evidence-based assessment, has the potential to point us towards a single narrative or argument leading to an incontrovertible conclusion in research.

Stepping back from the micro to the macro level, it has also been argued that many key scientific or sociological advances are themselves based on ungrounded assumptions, or on a persuasive narrative, in favour of a particular position at the expense of alternatives (Bloor 1991 [1976]). These grand narratives of science and of our contemporary society are not deliberate attempts to mislead, but are based on a series of motivated decisions that are to some extent discretionary. In other words, we have chosen certain data in preference to others and in another time and in another place we might have had reasons to prefer different data and come to different conclusions. Bloor's scepticism is sufficiently radical that one might conclude that unmotivated decisions are impossible and every alterntive universe would be equally valid. However, it is the purpose of his Strong Programme in the sociology of scientific knowledge to simply problematize some of the fundamental assumptions of our scientific belief systems rather than to refute them. At this macro level the activity-theoretic conclusion is neither that evidence-based assessment must provide a robust foundation to any research evaluation, nor does it point towards a singular narrative or framework within which research must necessarily be assessed. So what does the activity-theoretic model offer?

If one takes Bloor's criticisms seriously, the impact on research and its assessment in interpretative areas such as creative arts is dramatic. Not only does it add to the argument for the equal legitimacy of qualitative with quantitative methods, it challenges many of the fundamental assumptions made within the Western intellectual tradition about the necessary connection between conservative models of thought and knowledge production (Searle 1993), thought and language (Whorf 1941), and broadens the paradigms of thought and understanding described by Guba and Lincoln (2005). By legitimising alternative ways of interpreting data, and indeed what we might accept as data, the field of architectural research is given a voice with which to express alternative socio-cultural values and to describe how these values give rise to alternative, productive insights and understandings to traditional models of academic research, i.e. significant research outcomes, based in professional practices, which have potential impact.

Institutions of legitimacy have gradually shifted. In medieval times the church legitimized all knowledge, and the universities evolved out of these monastic institutions carrying forward their power to determine what constitutes new knowledge. Later one can identify a distinction between practical and professional knowledge on the one hand - which was learned through the system of 
apprenticeships and was legitimized by the medieval guilds - and academic knowledge that was legitimized by the universities on the other. Bourdieu has argued that there is a struggle for legitimacy between these societally authorized institutions and one might conclude that in contemporary times the universities have emerged as the dominant legitimizing power (Bourdieu 1988 [1984]). But according to a socio-cultural perspective, it is not so much that one institution dominates the other by virtue of the power of its knowledge-creating tools, so much as one institution emerging as societally dominant over another. Deer (2002) observes that the dominance of the university over the polytechnic in the higher education sector in the UK was a consequence of political decisions based largely on perceptions of increased economic efficiency rather than any fundamental superiority of academic knowledge production over professional know-how.

Instead of thinking that either reality, i.e. our data, or the nature of a particular field and its narratives; determine a professional activity; I would like to address this the other way around. We can diagnose the implicit values that are held in a field from the authorized activities of members of that field. If we look at the hard sciences, we can see that the procedures adopted in science tend to minimize the role of the opinions and the personality of the individual scientist herself, and maximize the claims that she is making for the objectivity of the findings. Broadly speaking, science tries to make claims about an external world that exists independently of the observer. This is a form of material Realism, and as a result, science tends to focus on the material aspects of this external world by looking at molecules and atoms, physical objects, chemical reactions, etc., and explaining them in causal ways that suggest that these actions and interactions go on independently of the observer. This explains why the scientist employs quantitative techniques that obviate the biases, interests and eccentricities of the individual person. This is based on a quite different set of basic assumptions from the ones made by the sociologist. The sociologist is interested in the social interaction of human beings that includes the opinions and personalities of the individuals concerned. It is essentially a science of the social world rather than a science of the material world. This explains why the sociologist employs qualitative techniques that value the biases, interests and eccentricities of the individual person. Even when adopting quantitative approaches, sociology has developed new methods of statistical analysis, such as Geometric Data Analysis, that reflect these complex relationships.

\section{Results and discussion}

At University of Hertfordshire we undertook some research using the data from the UK Research Assessment
Exercise 2008 (Biggs and Büchler 2013). The RAE data is organised in fields including one called "output type". The output type records whether a research output is a journal article, a book, a building, etc. On reflection the mere presence of this category tells us something about research and research methods. It apparently says that an artefact or a design or a piece of music is not itself a research method, but an output type. Now perhaps nobody in creative arts was claiming that a building, a design, or a musical composition is a research method, but I suspect we can find some such claims in the literature. In earlier research I undertook an ontological investigation into research methods in creative arts and asked the question "what is the function of a research method?". I concluded that a research method in any discipline has a structural role that connects the research issue to the research outcome or response (Biggs and Büchler 2007). If an appropriate research method is chosen, then it ensures at the answer is meaningfully connected to the question and that the results or conclusions that are obtained are legitimate in the eyes of the community who recognise the appropriateness of the research method to the task at hand (Biggs 2004). In terms of the present article this could be called an activity-theoretic account. This structural description also suggests that the research method occupies a position in between the research question and the research outcome (Biggs and Büchler 2008), which corresponds to the differentiation by the RAE 2008 between an output type and a research method. In other words, we have research question in Position 1, we have research methods and activities in Position 2 and we have conclusions, artefacts, outcomes and output types in Position 3.

More recently I have rejected my previous ontological approach to understanding the nature of research, in favour of an explicitly socio-cultural approach (Biggs and Büchler 2011). In a socio-cultural approach one does not look for fundamental definitions or criteria as one does in the ontological approach, and one looks instead for community endorsement and authorisation of certain practices. If one looks at research conducted in creative areas one will find that making a building or a design or a piece of music is regarded by some of the community as a legitimate research activity (JAR 2013). In terms of the activity-theoretic model above, Position 2 is legitimized by the interpretative community who find the questions in Position1 worth asking, and the answers in Position 3 satisfying. As a result, we need to ask what kind of research methods are legitimised by the community and lead to valid and significant research outputs such as buildings, designs and music?

Research methods have a particular role within what can be called the "research net". The traditional academic research net, which is derived from the hypothetico-deductive scientific method, includes an explicit research question or topic, the context in which this topic arises including the 
research work of other people in the field, the research methods that will be used in order to gather and analyse information or artefacts that are relevant to the question, and the outcomes of the research in terms of answers, responses, collections of work, exhibitions, etc. In some cases outputs and outcomes are differentiated, where the former are things that are created during the research project, and the latter are the conclusions, findings or "results".

Activity theory interprets research methods as having an instrumental role to play in getting us from our question to our answer - they are integral to Wittgensteinian therapy for stuck epistemologists. The starting point is the research question but in framing the next few stages we will want to keep an eye on the kind of outputs that we are interested in generating. As an architect we will, quite legitimately, have an interest in ensuring that some of the outcomes will be buildings, i.e. retro-fitting the question to the methods. Indeed, this may be a requirement of a funding agency or an end result such as an commissioned project. This will frame the range of methods that we think are relevant to our enquiry because these methods must produce architecture. But inasmuch as the production of architecture is some kind of response to the question, so the research method is formative of of this architectural production. This can be seen at work in the architect's studio when Schön (1983) adopted an ethnographic approach to observing the teacher and the student. The teacher tries to "frame" the question in was that facilitate a designed response by the student. Other ethnographic descriptions of the process reveal the instrumentality of the educational process (Cuff 1992), or of the studio itself (Yaneva 2009) in determining acceptable responses. More broadly, and non-architecturally, if I am a sociologist I might always be interested in what people have to say about their environment and therefore I will always want to ensure that my research methods include talking to people, interviewing them, reading what they have written such as their diaries, finding historical accounts by people from the past, etc. Depending on my research question I may choose a research method such as semi-structured interviews or ethnographic participant-observation in order to gather data that has the potential to tell me something about my research question. In such cases, the interviews that are gathered form the data for subsequent analysis. Alternatively the visual artist may generate artworks that form data for subsequent analysis. The sociologist or ethnographer will need a particular technique in order to analyse the written accounts that form the data. The selection of data and the form of analysis constitute the research method. If visual designs form data within a project then that data will need to be analysed using an explicit research method such as visual content analysis, etc.
On the other hand we need to address the situation in which the creative products are more integral to the research and are not merely data. We could imagine a journey that the artist takes and that the journey through the landscape is in some ways documented by the production of artefacts. In such cases it seems to me that the rationale for producing artworks is one of documentation, but also one in which there is some kind of re-creation or symbolic or metaphorical manifestation of the landscape experience had by the artist that is in some way recreated in the exhibition. In a project of this kind the research method would be the particular way in which the artist has imported or represented the landscape experience into the artwork. This may be explicitly encoded such as happens in the case of process art, e.g. the poet Kenneth Goldsmith, that requires us to be familiar with the style of the artist in order to understand what it is that he or she does when she brings us an experience through the format of the exhibition. In either case, or anywhere in the scale of possibilities in between, the mere production of the artwork is not the method but how the production of artwork addresses the question and leads us to the outcome of the research. Thus a research method is a link in the chain that validates the selection of data and the production of outputs such as paintings or buildings.

I have previously defined the research method as determining the connection between the research answer and the research question (Biggs and Büchler 2007). We can evaluate the rigour of the research method by the persuasiveness with which it will take us from the question to the answer. An inappropriate or invalid research method will either not generate an answer to the question, or will not result in a meaningful or significant answer to the question. In this context, "meaningful" responds to the fitness for purpose of the answer, i.e. an architectural answer to an architectural question; and the "significance" responds to the impact of the answer or its contribution on the community who uses it. One could object to an inappropriate research method by saying "if I wanted to answer that question I would not to that". Thus if the architectural researcher wants to make buildings, she must ask herself in what way, or perhaps what kind of buildings, would be relevant in response to this question in order to take us towards some kind of insightful outcome that will be relevant to other architects.

I had a student who made landscape art. In the beginning the artworks were abstract representations of the landscape. During his research he became interested in the literal processes that we used to shape the landscape during activities such as quarrying and road building. He characterised these processes as scraping, scratching, sorting piles of debris into heaps, etc. He went on to 
employ scraping, scratching and sorting activities in the creation of his artworks, thereby in some way making his art production analogous to the production of the landscape through industrial processes. The connection between his artwork and the landscape that it depicted, changed from one of visual representation into one of symbolism or analogy. I would describe his research method has something that emerged from his professional practices as an artist. He came to understand that he had a particular kind of relationship to the landscape when he was representing it pictorially, as he did in the beginning. Through an increased awareness of alternative relationships to depicting landscape, he developed a number of production techniques based on analogies to industrial processes. Thus we could say his research method was to develop art processes based on analogy with industrial production processes rather than through visual representation. Through employing this method, he produced artworks. He could account for the relationship of his artworks to the landscape through his research method. He could therefore account for the way in which his artworks acted as novel kinds of landscape depiction by understanding not only the relationship of his artwork to his landscapes but the ways in which other kinds of landscape art stand in relation to the landscape that they depict. The key outcome of the research, apart from the artworks themselves, was an awareness and a sharing of this tool. The tool (analogous production techniques) is the part that is transferable to others and therefore of significance to the community. The artworks themselves "demonstrate the operability of the tool" to use established research terminology.

It is quite common in creative arts research, indeed maybe it is even some kind of definition of such research, that the researcher should want to produce paintings, sculptures, dance performance, buildings, etc., as part of the research process. These buildings, designs, and other creative outputs, and in particular the creative processes, are often claimed to be the methods of creative arts research. I believe that this is a category mistake. Buildings, designs, etc. are some of the outputs of creative arts research. Other outputs may include, although they do not necessarily have to include, written documentation of processes, data sets, etc. It is also possible that artefacts are produced that become the data that are subject to analysis during a research project. However, what I want to differentiate, is that the production of creative works is not itself a research method. I believe that producing designs is not a method, but a form of outcome. The method has a particular role of shedding light on the research problem. Wanting to produce architecture is like wanting to talk to people: it determines what kind of activity the person wants to do rather than constituting a method.

\section{Conclusions}

The conclusion is not that we cannot undertake research through the practice of making, or through research by design, etc. Instead, it throws our focus on to what would constitute a research method in such a practice. I believe we need to rethink the whole notion of what would constitute research as an activity within the creative arts paradigms. It is unsatisfactory to simply map our existing scientific or sociological activities onto the creative arts. This mapping does not make sense because the objectives of our activity are quite different. Therefore, because research methods connect the legitimacy of the outcome to the issue being investigated, it makes no sense to undertake a legitimate scientific activity in pursuit of objectives in architecture and urbanism. So my conclusion is that we must reconsider the whole package: what are we trying to achieve, what are our objectives, and how do we make a valid, useful, meaningful, and significant contribution to the issue at hand?

We have to bear in mind that the objectives of creative arts research are themselves creative arts outputs. So one of the objectives is to generate a creative output, such as a building or a design: to do architecture. This is an objective but it is not the only objective. We also require the outputs to make a particular contribution: to have a particular relationship to the general field and the topic being investigated and to offer potential for significance. This is what will characterise the output as a research contribution rather than a studio contribution or simply a building. I have said elsewhere that research is an intentional activity, in which we direct our activity towards a particular goal. Although in the creative arts we are probably more open to serendipitous outcomes, research is nonetheless a selective process in which we reject some activities and outcomes in favour of others, bearing in mind the topic to be researched. We therefore require a decision-making framework within which we can judge the suitability of activities for our academic purpose in relation to the external framework which will judge the suitability of the outcomes as professionally impactful architecture, urban design, etc. This could constitute a Strong Programme of the type established by Bloor and claimed to some extent for urban studies by Farías and Bender (2010). However, the latter see the tendency in urban studies to be structuralist whereas what is proposed here is activity-theoretic. The main difference relates to focussing on what counts as data rather than how that data is interpreted. Socially engaged thick description has been undertaken in regard to architecture (Awan et al. 2011; Yaneva 2009) using Actor-Network Theory, although they differentiate between a "pragmatist" approach that calls upon descriptive pre-theoretic positions from within architecture, and what they would call a "critical" approach that calls on resources from outside architecture (Yaneva 2009). The 
outcome of such a critical approach is the identification of the attitudes, beliefs and dispositions of interpretative communities themselves.

Such a critical activity-theoretic framework needs to be constructed before we can assess the appropriateness of an activity as a method of knowledge production, and such a framework needs to be grounded in an analysis of the values and aims of the discipline of architecture. Initially it will need to be done on a project-by-project basis in which the appropriateness of the method is made explicit. As the corpus of impactful projects grows so the community, or even its assessors such as ERA, PBRF, RAE, etc., will be able to make transferable statements about methods in general. Once this is done by the architectural community it will be apparent which activities have the potential to add knowledge that is valued by both the academic and the professional peers, and not solely valued by the established hegemony of legitimation in academia. It will also have the added benefit of bridging the academic and professional divide that has been exacerbated by the migration of education in architecture and urbanism from the studio into the university. Finally, it will respond to the foundational question of what activities have validity in research by design, and in what ways doing architecture is doing research.

\section{Competing interests}

The author declares that he has no competing interests.

\section{Acknowledgements}

The author would like to acknowledge the support of the Australian

Research Council (DP130100402) and the UK Arts and Humanities Research Council (AH/F009828/1) in funding the research that underpins this article.

Received: 23 June 2014 Accepted: 29 November 2014

Published online: 23 December 2014

\section{References}

Awan N, Schneider T, Till J (eds) (2011) Spatial Agency: Other Ways of Doing Architecture. Routledge, London

Biggs MAR (2004) Learning from Experience: Approaches to the Experiential Component of Practice-based Research. In: Karlsson H (ed) ForskningReflektion-Utveckling. Swedish Research Council, Stockholm, Sweden, pp 6-21

Biggs MAR, Büchler D (2007) Rigour and practice-based research. Design Issues 23(3):62-69

Biggs MAR, Büchler D (2008) Eight criteria for practice-based research in the creative and cultural industries. ADCHE 7(1):5-18, doi:10.1386/adch.7.1.5_1

Biggs MAR, Büchler D (2011) Communities, Values, Conventions and Actions. In: Biggs $\mathrm{M}$, Karlsson $\mathrm{H}$ (eds) The Routledge Companion to Research in the Arts. Routledge, London, pp 82-98

Biggs MAR, Büchler D (2013) Inferring a collective concept of research from the actions of the art and design research community. ADCHE 12(1):7-19, doi:10.1386/adch.12.1.7_1

Bloor D (1991 [1976]) Knowledge and Social Imagery, 2nd edn. University of Chicago Press, Chicago

Bourdieu P (1988 [1984]) Homo Academicus (trans: Collier P). Polity Press, Cambridge

Coyne R (2009) Interpretative communities as decisive agents: on pervasive digital technologies. Archit Res Q 13(2):127-132

Cuff D (1992) Architecture: the Story of Practice. MIT Press, Cambridge, MA
Deer CMA (2002) Higher Education in England and France since the 1980s. Symposium Books, Oxford

Engeström Y, Miettinen R, Punamäki R-L (1999) Perspectives on Activity Theory. Cambridge University Press, Cambridge

Farías I, Bender T (eds) (2010) Urban Assemblages: How Actor-Network Theory Changes Urban Studies. Routledge, London

Feyerabend P (1993 [1975]) Against Method. 3rd edition edn. Verso Books, London

Gibson JJ (1986 [1979]) The Ecological Approach to Visual Perception. Psychology Press, Mahwah, NJ

Guba E, Lincoln Y (2005) Paradigmatic Controversies, Contradictions and Emerging Confluences. In: Denzin N, Lincoln Y (eds) Sage Handbook of Qualitative Research, 3rd edn. Sage, London, pp 191-215

Hirsch ED (1984) Meaning and significance reinterpreted. Crit Inq 11(2):202-225

JAR (2013) Journal for Artistic Research. Society for Artistic Research. http://www. jar-online.net/. Accessed 10 December 2014

Latour B, Woolgar S (1986) Laboratory Life: The Construction of Scientific Facts. Princeton University Press, Princeton, NJ

Popper KR (2002 [1963]) Science: Conjectures and Refutations. In: Conjectures and Refutations. Routledge, London, pp 43-86

Schön DA (1983) The Reflective Practitioner: How Professionals Think in Action. Temple Smith, London

Searle JR (1993) Rationality and realism, what is at stake? Daedalus 122(4):55-83

Till J (2011) Is Doing Architecture Doing Research? Paper presented at the 4IAU 4a Jornadas Internacionales sobre Investigación en Arquitectura y Urbanismo. Universitat Politècnica de València, Valencia

Whorf B (1941) The Relation of Habitual Thought and Behavior to Language. In: Spier L (ed) Language, Culture, and Personality, Essays in Memory of Edward Sapir. Sapir Memorial Publication Fund, Menasha, WI, pp 73-95 Wittgenstein L (1953) Philosophical Investigations. Basil Blackwell, Oxford

Yaneva A (2009) The Making of a Building, a Pragmatist Approach to Architecture. Peter Lang, Bern

\section{doi:10.1186/s40410-014-0016-z}

Cite this article as: Biggs: An activity theory of research methods in architecture and urbanism. City, Territory and Architecture 2014 1:16.

\section{Submit your manuscript to a SpringerOpen ${ }^{\circ}$ journal and benefit from:}

- Convenient online submission

Rigorous peer review

- Immediate publication on acceptance

- Open access: articles freely available online

- High visibility within the field

- Retaining the copyright to your article

Submit your next manuscript at $\gg$ springeropen.com 